\title{
Dendritic Fluoroalcohols Catalyzed Alkene Epoxidation with $\mathrm{H}_{2} \mathrm{O}_{2}$
}

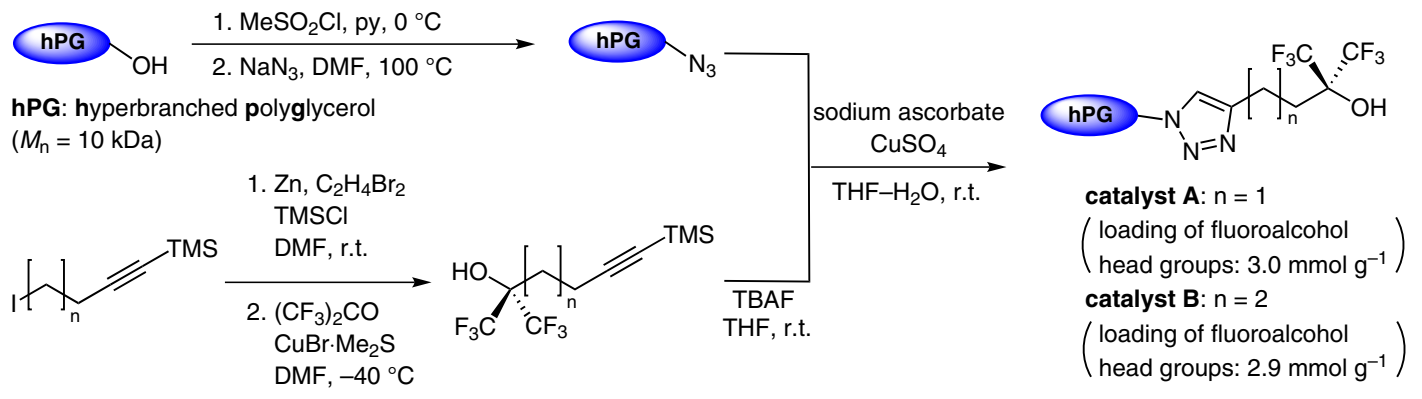

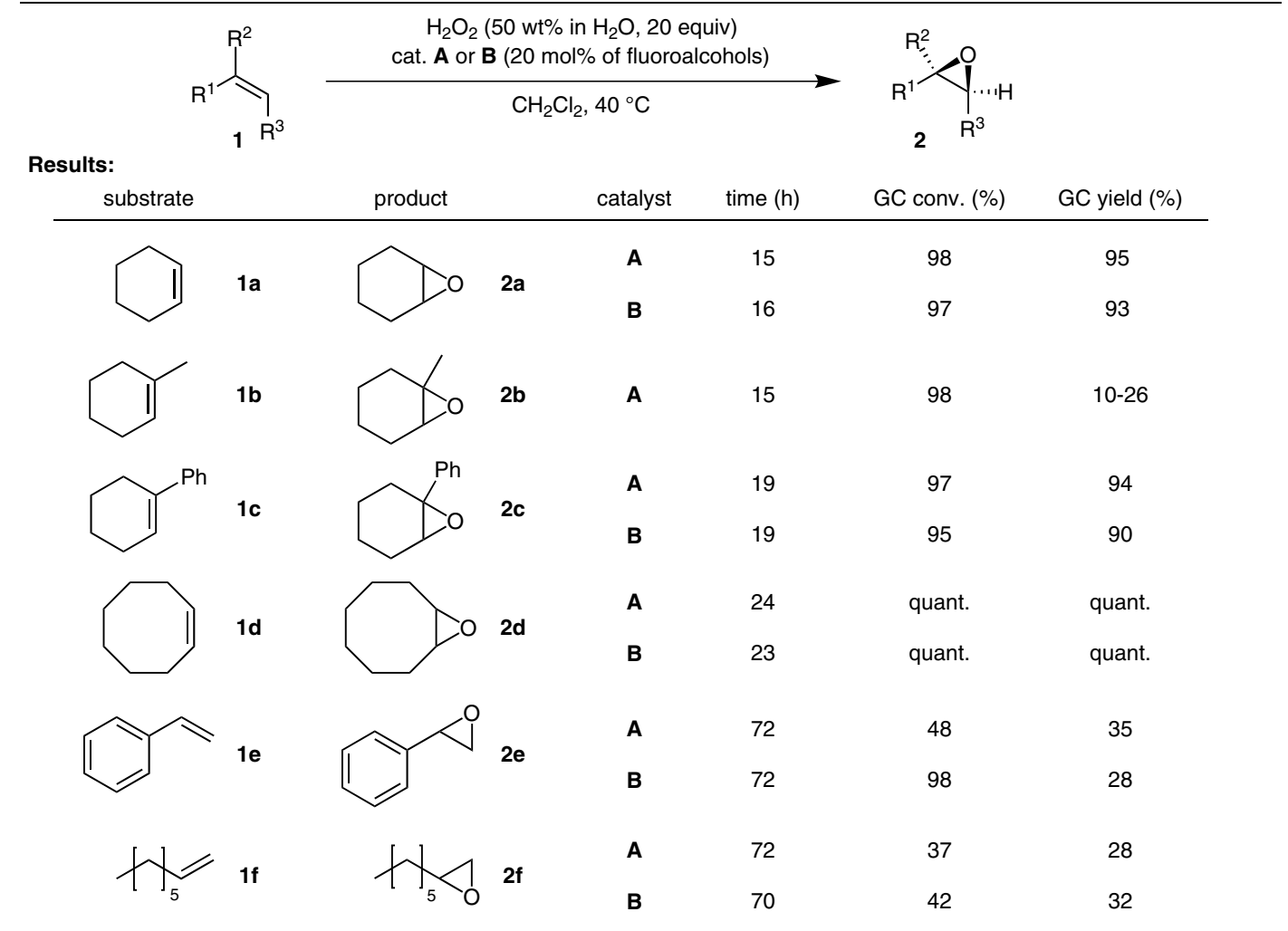

Significance: Hyperbranched polyglycerol immobilized flluoroalcohols (catalyst $\mathbf{A}$ and $\mathbf{B}$ ) were prepared and applied to the epoxidation of alkenes. Thus, the reaction of alkenes 1 and aqueous hydrogen peroxide with $20 \mathrm{~mol} \%$ of the fluoroalcohol unit of the catalyst gave the corresponding epoxides 2 in up to quantitative yield.
Comment: Catalysts $\mathbf{A}$ and $\mathbf{B}$ were recovered by ultrafiltration (molecular-weight cut-off of the membrane: $5 \mathrm{kDa}$ ) and reused twice for the epoxidation of cyclooctene without significant loss of catalytic activity. Hexafluoro-2-propanol showed lower catalytic activity for the epoxidation of $\mathbf{1 d}$ under similar conditions (24 h, 2d: 14\% yield).

synfacts Contributors: Yasuhiro Uozumi, Yoichi M. A. Yamada, Aya Ohno

Synfacts 2013, 9(4), $0451 \quad$ Published online: 15.03.2013

DOI: 10.1055/s-0032-1318422; Reg-No.: Y02313SF 